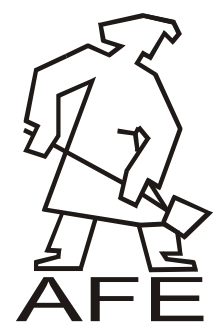

ARCHIVES

of

FOUNDRY ENGINEERING

ISSN (2299-2944)

Volume 13

DOI: 10.2478/afe-2013-0055

Issue $3 / 2013$

\title{
Environmentally Friendly Mould Technology
}

\author{
I. Izdebska-Szanda *, A. Palma, M. Angrecki, M. Żmudzińska \\ Foundry Research Institute, Zakopiańska 73, 30-418 Krakow, Poland \\ *Corresponding author. E-mail address: irena.szanda@iod.krakow.pl
}

Received 28.05.2013; accepted in revised form 31.05.2013

\begin{abstract}
One of the factors that contribute to the development of foundry moulding technology is environmental protection. The related challenges are effectively satisfied by a new inorganic binder that has been designed for castings made of non-ferrous metal alloys.

This article presents in a concise way the test results, showing the ecological character of the new binder at the stage of making moulds, pouring them with metal and cooling of castings, indicating the possibilities for an economic re-use of waste materials formed during practical application of this technology. The results were compared with the results obtained on the sands with organic binders.

Studies were carried out under the project POIG.01.01.02-00-015/09 "Advanced materials and technologies."
\end{abstract}

Keywords: Innovative foundry materials and technologies, Modified inorganic binders, Technological properties, Ecology, Postreclamation waste management

\section{Introduction}

With the ever-increasing demands on environmental protection, increasingly important are also becoming the technologies that, while ensuring the required technological parameters, can bring the least possible harm to the environment.

Hydrated sodium silicate is an inorganic binder, which belongs to the family of environmentally friendly materials. Although foundry sands with this binder are of a versatile character, relatively cheap and exhibiting a number of other advantages, their high ultimate (residual) strength, and hence poor knocking out properties, make them "great loser" in the competition with organic binders, furan resins in particular [1].

The use of chemically modified inorganic binders has as a main aim reducing the disadvantages, such as the poor knocking out properties, low elasticity and the related worse reclamability, especially as regards water glass, i.e. the inorganic binder used so far by the foundry industry, thereby facilitating its wider use for casting of nonferrous metal alloys, while maintaining its eco-friendly character [2-5].

\section{Aim of the investigations, methodology and materials tested}

The aim of the structural project is to introduce new, modified, ecofriendly inorganic binders to the production of foundry moulds and cores in casting of non-ferrous metal alloys (including the recycling and disposal of the waste moulding sand).

Therefore, new types of binders developed under the project [6-10] have been tested, to assess the effect of chemical modification of hydrated sodium silicate on the technological characteristics of moulding sand, on its knocking out properties and reclamability, and on the thermal destruction of moulding sand in terms of its harmful impact on the natural environment and work conditions.

The results presented in this article are a partial summary of studies carried out under the project to assess the ecological aspect of the technology.

Two types of inorganic, modified binders designated by the symbols "A" and "B" were used in the studies.

The reference binder was designated by the symbol ' $\mathrm{O}$ '- it was unmodified hydrated sodium silicate. 
Batches of binders for laboratory tests were prepared by the manufacturer of inorganic binders - Vitrosilicon in Iłowa. The hardener for the sands with the tested inorganic binders was ester hardener called Flodur 1.

As a reference moulding sand, the sand with an organic binder in the form of an X850 furan resin was used.

Moulding sands and moulds for technological tests were based on the $1 \mathrm{~K}$ silica sand from Szczakowa mine (now DB Schenker) with the main fraction of $0.20 / 0.40 / 0.315$.

Test moulds were poured with aluminium and copper alloys.

\section{Own tests and investigations}

\subsection{Effect of chemical modification of hydrated sodium silicate on selected technological properties of moulding sands}

Based on past experience [6, 7], two types of organofunctional, morphoactive, organic modifiers were selected. They were designated as a modifier "A" (a synthetic thermoplastic polymer) and a modifier "B" (a copolymer obtained by emulsion polymerisation). Modification consisted in introducing to the hydrated sodium silicate with a silicate modulus $\mathrm{M}=2$ and a density of $1.5 \mathrm{~kg} / \mathrm{m}^{3}$, a modifier in an amount of $1.0 \%$ relative to the total of oxides $\left(\mathrm{Na}_{2} \mathrm{O}, \mathrm{SiO}_{2}\right)$ under the conditions of elevated pressure and temperature.

Using selected inorganic binders and a hardener in the form of ethylene glycol diacetate (flodur 1), moulding sands were prepared containing 2.5 parts by weight of binder and $10 \%$ of hardener (calculated relative to the binder weight). A reference moulding sand with an organic binder designated by the symbol " $Z$ " was the sand with the X850 furan resin, added in an amount of 0.9 part by weight and hardened with a 100T3 hardener added in an amount of 0.45 part by weight. The ready sand mixtures were subjected to a technological evaluation, including the bench life, permeability, compression strength and bending strength.

Figure 1 shows the values of the bending strength obtained in samples of the moulding sand prepared with the examined types of binders.

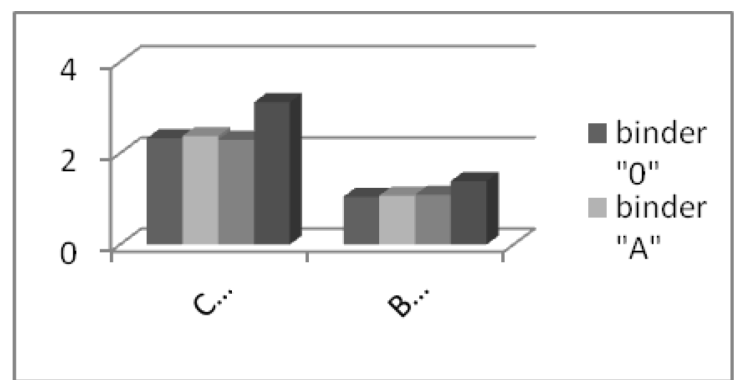

Fig. 1. The results of the sand strength testing under ambient conditions

For each binder, tests were also conducted at elevated temperature, to determine the, so-called, residual strength, which is an indirect indicator of the moulding sand knocking out properties. The results are shown in Figure 2.

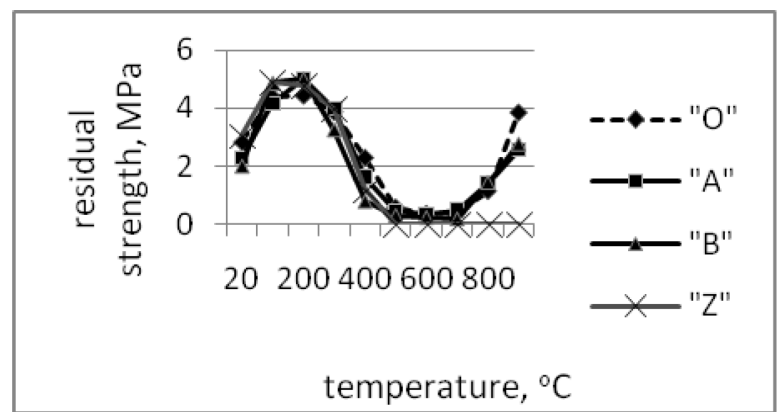

Fig. 2. The results of the residual sand strength testing

The technological properties of moulding sands with inorganic binders of a new generation in the form of chemically modified hydrated sodium silicate, tested under ambient conditions, have remained basically unchanged compared to the corresponding properties of moulding sands with the unmodified silicate binder. On the other hand, a marked improvement was observed in the technological properties at elevated temperatures, especially in the range of $400^{\circ} \mathrm{C}$ to $700^{\circ} \mathrm{C}$.

\subsection{Effect of chemical modification of hydrated sodium silicate on the thermal destruction of moulding sand}

Every new binding system used in moulding sand should be assessed in terms of its possible harmful impact on the environment [11, 12].

Tests were carried out on moulding sands " 0 ", "A" and "B" and, for the sake of comparison, on a reference sand "Z". A weighed sample of the tested moulding sand was introduced into a quartz tube placed in a PR-45/1200MF resistance furnace heated to an appropriate temperature. The destruction time was 30 minutes with the air flow rate of $10 \mathrm{ml} / \mathrm{min}$. Studies of the destruction were conducted at a temperature of $500^{\circ} \mathrm{C}$ and $800^{\circ} \mathrm{C}$. The decomposition products were subjected to chemical analysis, determining the type of the chemical compounds emitted.

The presence in an ester hardener (ethylene glycol diacetate used as a hardener of sands with inorganic binders) of free acetic acid, ethylene glycol and ethylene glycol esters makes this hardener a potential source of the emission of harmful substances. Based on the analysis of the results of the study it was found that sands made with the hydrated sodium silicate and ethylene glycol diacetate mainly emit harmful substances such as formaldehyde, acetic acid and carbon monoxide, larger amounts of these compounds being emitted at a temperature of $500^{\circ} \mathrm{C}$.

In the case of the reference moulding sand with an organic binder ("Z"), the main products of its thermal decomposition include carbon monoxide and sulphur dioxide, where the amount of the emitted carbon monoxide decreases with increasing temperature, while the amount of sulphur dioxide is growing. Nitrogen oxides are components of the gaseous phase occurring in lower volumes. In the gaseous products of the destruction of moulding sand " $Z$ " also the presence of ammonia was traced. Its measured amounts were increasing with increasing temperature of the decomposition. At high temperature $\left(800^{\circ} \mathrm{C}\right)$, the emission rate of toluene, benzene, and xylene was much lower. 
The conducted studies enabled determination of the laboratory toxicity indeces TL - Figures 3 and 4.

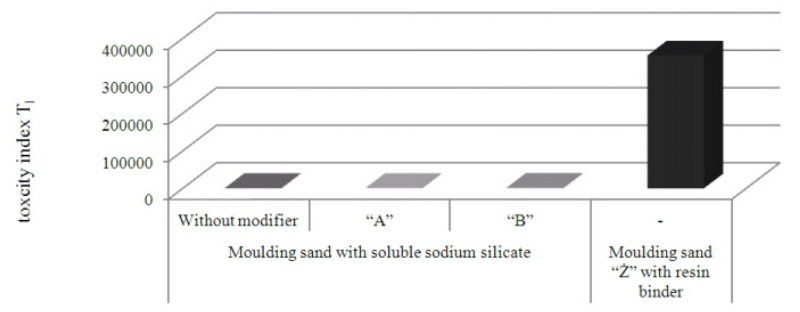

Fig. 3. Laboratory toxicity indeces calculated for the tested sands

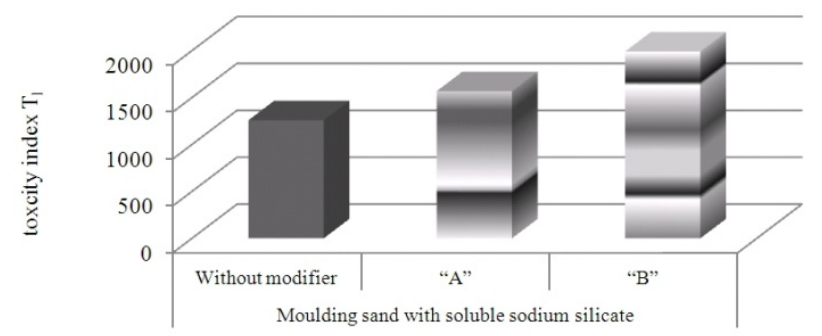

Fig. 4. Toxicity indeces of moulding sands with modified and unmodified binders

Comparing the values of the laboratory toxicity indeces $T_{L}$ of the tested sands with hydrated sodium silicate it has been found that binder modification and the type of hardener have but only very insignificant effect on the harmfulness of these sand mixtures.

Studies of the gas evolution rate at $500^{\circ} \mathrm{C}$ and $800^{\circ} \mathrm{C}$ indicate that the type of the modifying additive has little effect on the sand toxicity index, compared with the toxicity index value of the moulding sand prepared with an unmodified hydrated sodium silicate. On the other hand, in moulding sand prepared with an addition of the organic binder, the toxicity index value is approximately 170 times higher than the value obtained in the sand made with an addition of the modified hydrated sodium silicate.

\subsection{Effect of chemical modification on the knocking out properties of moulding sands}

Moulding sands with selected binders were subjected to technological evaluation making test moulds and determining the modification effect on knocking out properties.

In the authors' own studies, two methods were used in parallel to determine the sand knocking out properties. This article presents the results of the knocking out test performed in accordance with the method recommended by Polish standard PN-85/H-11005. The method consists in a technological trial, in which the measure of sand collapsibility is the work ( $\mathrm{Lw})$ needed to remove the core from casting.

Moulds and cores to test the sand collapsibility were prepared with both new modified inorganic binders, and for comparison with the unmodified hydrated sodium silicate and with an organic binder. In these moulds, castings were made from an Al-Si alloy (AlSi9 alloy) and from a copper alloy ( $\mathrm{CuZn59}$ alloy).
Test castings, after knocking out and cooling to ambient temperature, were placed together with cores in a device for testing of the knocking out properties and the number of blows of the weight necessary to remove the core from casting was measured.

The results of these studies are shown in a graph in Figure 5.

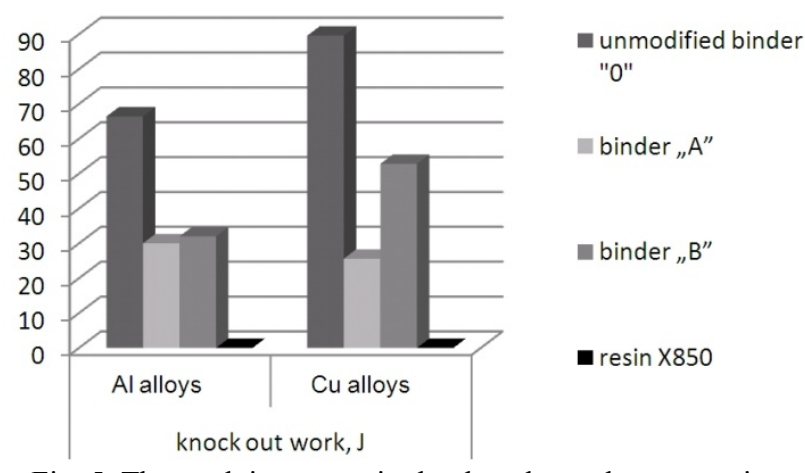

Fig. 5. The work input required to knock out the test castings made from $\mathrm{Al}$ and $\mathrm{Cu}$ alloys in sands with binders from industrial trials

Compared to unmodified binder, the sand mixtures prepared with new types of binders have much better knocking out properties, especially in the case of aluminium alloys.

\subsection{Evaluation of the environmental impact of the examined moulding sands during pouring and cooling of castings}

During pouring of test moulds for the knocking out trials, the sand mixtures with selected binders were subjected to an evaluation of their ecological aspect, which enabled determining the rate of the evolution of the gaseous pollutants in the process of metal casting and solidification. A test procedure was developed for these moulding sands to determine the amount of chemical compounds emitted under conditions similar to the real ones (Fig. 6, 7).

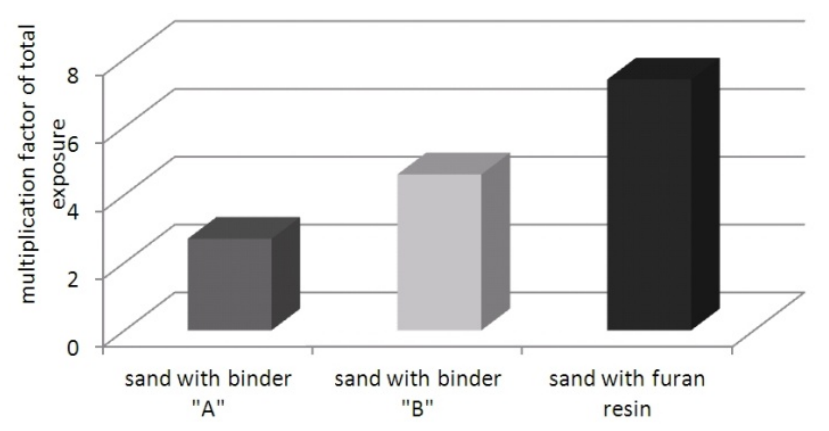

Fig. 6. Comparison of the coefficients of total exposure of workers to the effect of chemical compounds emitted from moulds poured with aluminium alloy (carcinogenic compounds included) 


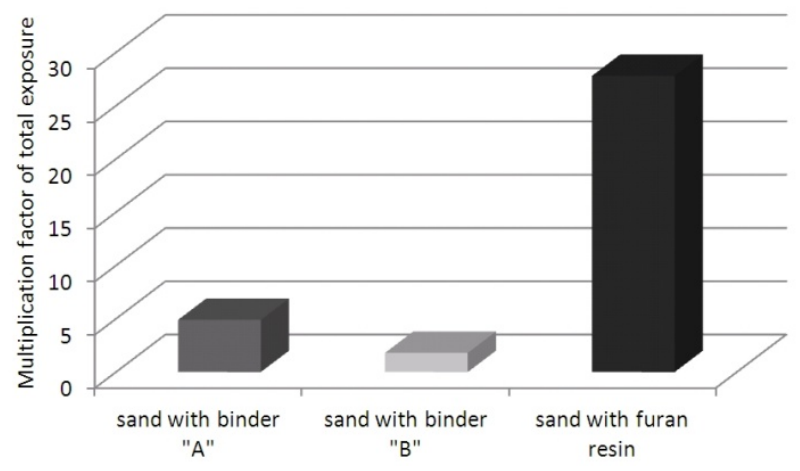

Fig. 7. Comparison of the coefficients of total exposure of workers to the effect of chemical compounds emitted from moulds poured with brass (carcinogenic compounds included)

Based on the survey performed and on the results obtained it was established that the lowest risk for foundry workers is created by the sands based on inorganic binders currently in use.

During pouring of moulds made from the sands with the new inorganic binder A and during manufacture of castings from aluminium alloys, the permissible limit value of formaldehyde was exceeded. In the case of the sand mixture based on binder B, both formaldehyde and ethylene glycol levels were exceeded. During casting of brass, in both sand mixtures A and B, the allowable concentrations of carbon monoxide were exceeded.

Furan resin sand used for casting of aluminium alloys resulted in exceeded hygienic standards for sulphur dioxide and benzene. In the case of brass castings, the exceeded permissible concentration values included ammonia, carbon monoxide, nitrogen dioxide, sulphur dioxide, benzene, and the total of PAHs.

Summing up it can be stated that among the examined sand mixtures, the least harmful to the work environment has proved to be the sand based on the new modified inorganic binder. The main source of pollution emitted from the tested sands containing the new inorganic binder is the ester hardener.

\section{Laboratory and industrial trials of sand reclamation and testing of the reclaim}

Good knocking out properties of the sand mixture are directly related with the reclamability of waste sands, which is a prerequisite for the effective waste management.

Therefore, within the framework of the project, tests and studies were carried out on the waste moulding and core sand mixtures prepared according to the new technology to determine the degree of recovery of the useful moulding material (the reclaimed sand) and the extent of its re-use in production process, including trials on the possible management of post-reclamation waste outside the foundry shop.

Reclamation tests were conducted under laboratory conditions on a pilot stand operating at the Foundry Research Institute and under semi-industrial conditions in a selected foundry shop (Hardtop Foundry in Charsznica, which has a reclamation stand of simplified design), conducted as a validation of the results under conditions similar to the real ones.
The sand reclaimed in industrial and laboratory trials was subjected to physico-chemical examinations (Fig. 8-10). The sand reclaimed in industrial and laboratory trials was next used as a component of the moulding mixture for further technological studies. Selected test results obtained for aluminium alloys are given in the form of graphs in Figures 11-12.

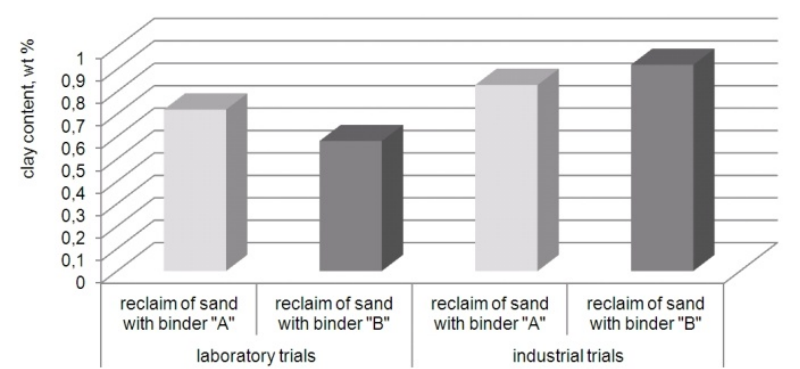

Fig. 8. Clay content in sand reclaims with binders from industrial and laboratory production - aluminium alloys

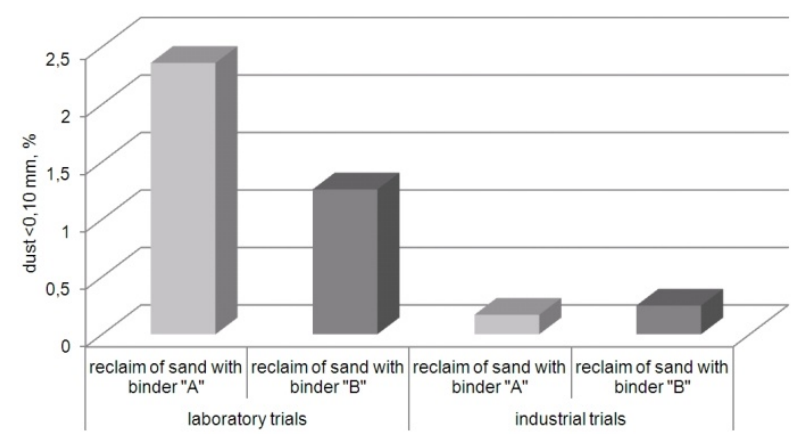

Fig. 9. Dust content in sand reclaims with binders from industrial and laboratory production - aluminium alloys

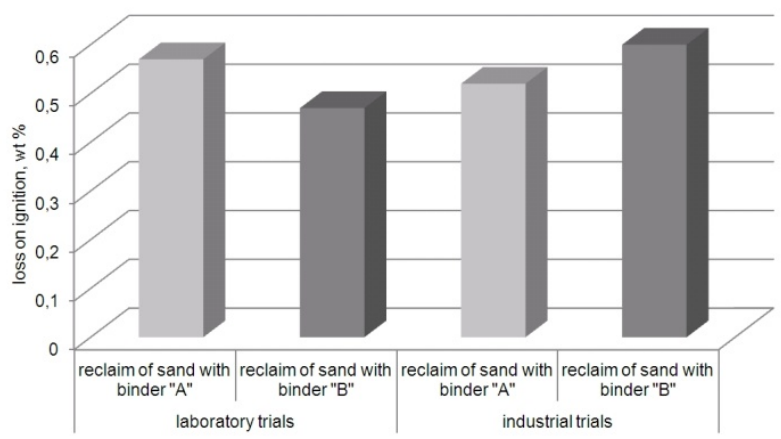

Fig. 10. Loss on ignition in sand reclaims with binders from industrial and laboratory production - aluminium alloys

The sand reclaim from industrial trial was less effectively cleaned from the binder envelope (simplified reclamation), but much better de-dusted, which was beneficial for the technological characteristics of the sand mixtures prepared with this reclaim. 


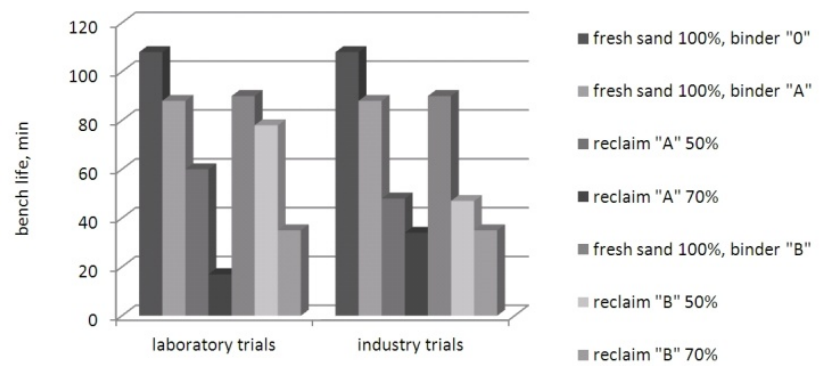

Fig. 11. Bench life of moulding sands with varied content of reclaim from laboratory and industrial trials -aluminium alloys

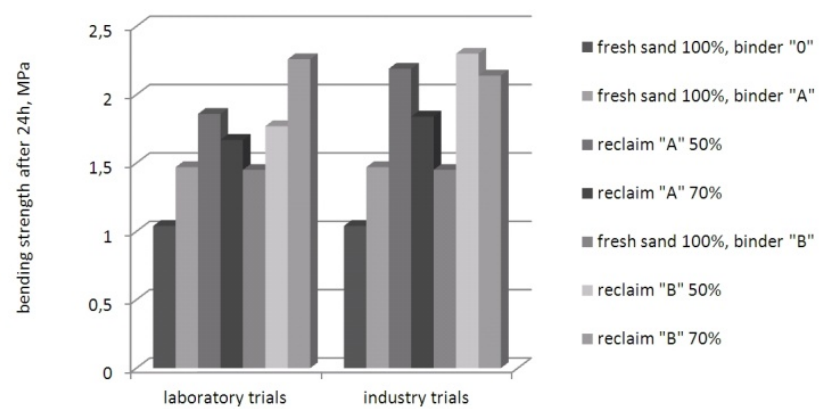

Fig. 12. Bending strength of moulding sands with varied content of reclaim from laboratory and industrial trials -aluminium alloys

Industrial trials have confirmed the possibility of using the reclaimed sand in an amount of up to $70 \%$ to replace fresh sand.

\section{Evaluation of potentials for the post- reclamation waste management}

The use of the reclamation process does not entirely eliminate the problem of waste (only changes its amount and nature), and therefore trials have been run for safe handling of such waste for the purposes other than the manufacture of castings. A methodology has been developed and studies have been carried out, including the pretreatment of waste as well as the technical and technological studies of its use, e.g. in applications such as the manufacture of products for cement industry or manufacture of building accessories.

\subsection{Trials to use post-reclamation waste in the manufacture of shaped ceramic elements}

From the clay, sand, reclaim and post-reclamation dust, cylindrical shaped elements of 50x50 dimensions were made. Their composition was as follows: $80 \%$ clay, $20 \%$ leaning material (sand). In the conducted tests, the sand was replaced with the reclaim and with post-reclamation dust.

From the ready mixture of the composition as stated above, cylindrical shaped elements were made on a laboratory press under a pressure of $3 \mathrm{MPa}$. After storage, drying and firing (at $1000^{\circ} \mathrm{C}$ ), the ceramic samples were tested for water absorption, capillary absorption, bulk density, compression strength and frost resistance.
In the determination of frost resistance $\mathrm{M}$ it has been assumed that if $M>0$, then the sample is resistant to frost. In these tests, the value of $\mathrm{M}$ ranged from 9,2-9,6.

Compression test was carried out in accordance with PN-EN ISO 8895:2007. The results of the test are shown in Figure 13.

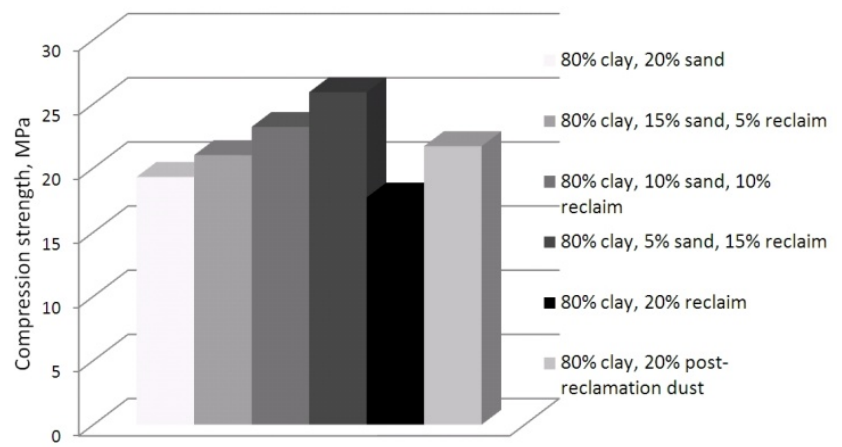

Fig. 13. The results of compression test performed on the ceramic shaped elements

Studies have shown that elements containing the addition of reclaimed sand or post-reclamation dust are resistant to frost, and their strength corresponds to the strength of the elements made with the new sand as a typical leaning material.

Preliminary laboratory tests to replace sand with reclaim or with post-reclamation dust in a ceramic mixture used for the production of bricks gave product characterised by properties similar to the properties recommended by relevant standard.

\subsection{Trials to use post-reclamation waste in the manufacture of shaped concrete elements}

The composition of the concrete mixture was established experimentally. From a mixture of cement, sand, reclaim, aggregate and water, cylindrical shaped elements of $\Phi 50 \times 50$ dimensions were made. Their composition was as follows: $1 \mathrm{~kg}$ sand + reclaim, $0.4 \mathrm{~kg}$ cement, $1.3 \mathrm{~kg}$ aggregate, $0.3 \mathrm{~kg}$ water.

The compression strength of the concrete shaped elements made in accordance with the standard was tested after a period of 14 and 28 days elapsing since the date they had been made. The results of these tests are shown in Fig. 14.
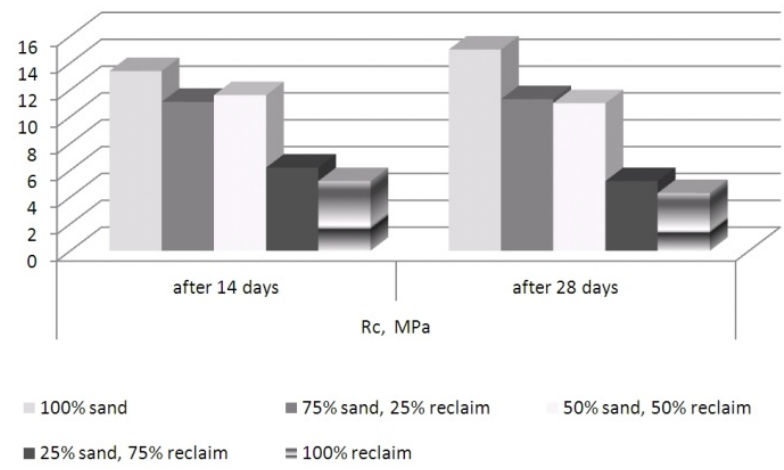

Fig. 14. The results of compression test performed on the concrete shaped elements with varied content of the reclaim 
The preliminary laboratory trials to replace sand in a concrete mix with the reclaim added in an amount of up to $50 \%$ gave product characterised by properties similar to the properties recommended by relevant standard.

This was confirmed by industrial trials carried out at the "Ryś" Company in Marszowice owned by Krzysztof Rudzki. The applied concrete mix contained: fine aggregate - mine sand $0-2 \mathrm{~mm} 250 \mathrm{~kg}$ $+250 \mathrm{~kg}$ reclaim; coarse aggregate: gravel (grit) $600 \mathrm{~kg}$; cement 32.5 $\mathrm{R}-170 \mathrm{~kg}$; make up water.

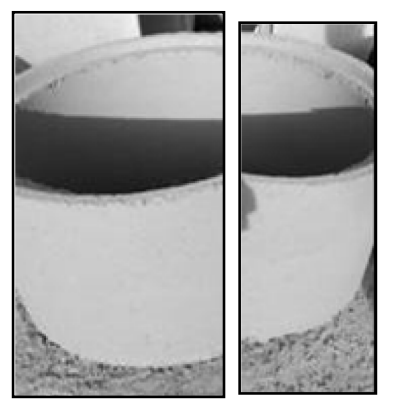

Fig. 15. Ready concrete products (rings) made from the concrete mix with and without the reclaimed sand

Concrete samples made during the industrial trial were subjected at the Foundry Research Institute to basic control tests. The density of concrete with the addition of reclaimed sand (according to PN-EN 12390-7) was $2250 \mathrm{~kg} / \mathrm{m}^{3}$, and the compression strength measured on specimens with the dimensions of $150 \times 150 \times 150 \mathrm{~mm}$ (according to the PN-EN 12390-1 Standard for testing of concrete products) - from 20-24 MPa.

The values of compression strength (20.0 to $22.4 \mathrm{MPa}$ ) obtained in specimens made in accordance with PN-EN 12390-1 allow qualifying this concrete as belonging to class C16/20 (according to PN-EN 2061:2004).

\section{Summary}

The conducted studies have confirmed that the proposed method of modification and binders obtained by this method allow achieving high technological parameters at both ambient and elevated temperatures (residual strength).

Tests on the knocking out properties of sand mixtures prepared with the addition of new, modified, inorganic binders have proved that by using binders of a new generation, a significant improvement can be achieved in the knocking out properties of foundry mixtures containing these binders.

The conducted tests lead to the conclusion that the amount of reclaim re-usable in the manufacture of moulding mixtures is up to $70 \%$.

The remaining material can be successfully used in the manufacture of building products (building ceramics and concrete items).

The main source of pollution emitted by the tested sand mixtures based on new inorganic binders is the ester hardener used in these mixtures. To reduce harmful emissions formed in the casting process, inorganic binders should be used.

The obtained results show the possibility and advisability of a full recycling of the waste moulding sands made with the new types of binders.

\section{Acknowledgements}

This paper presents the results of studies carried out under the project POIG.01.01.02-00-015/09 "Advanced Materials and Technologies", Area VII Task 3 "Environmentally friendly mould and core technologies for casting of non-ferrous metals, including their recycling and disposal" co-funded by the European Union and the State budget.

\section{References}

[1] Baliński, A. (2009). About structure of hydrated sodium silicate as a binder of moulding sands. Cracow: Foundry Research Institute.

[2] Stechman, M., Różycka, D. \& Baliński, A. (2003). Modification of aqueous sodium silicate solutions with morphoactive agents. Polish Journal of Chemical Technology. $5(3), 47$.

[3] Jelinek, P. \& Skuta, R. (2003). Modified sodium silicates a new alternative for inorganic foundry binders. Materials Enginering. 10(3), 283.

[4] Izdebska-Szanda, I. (2009). Moulding sand with silicate binder characterized by beneficial technological and ecological properties. Unpublished doctoral dissertation, Faculty of Mechanical Engineering and Management, Poznań University of Technology, Poznań.

[5] Vasková, I. \& Bobok, L. (2002). Some knowledge of the water glass modification by the phosphate compounds. Acta Metallurgica Slovaca. 8(2), 161-167.

[6] Izdebska-Szanda, I., Szanda, M. \& Matuszewski, S. (2011). Technological and ecological studies of moulding sands with new inorganic binders for casting of non-ferrous metal alloys. Archives of Foundry Engineering. 11(1), 43-48.

[7] Izdebska-Szanda, I., Baliński, A. (2011) New generation of ecological silicate binders, ELSEVIER, 2011 from Elsevier Ltd. http://dx.doi.org/10.1016/j.proeng.2011.04.146. DOI: 10.1016 .

[8] Izdebska-Szanda, I., Baliński, A. \& Angrecki, M. (2012). Evaluation of reclamability of moulding sands with new inorganic binders. Archives of Foundry Engineering. 12(2), 35-40.

[9] Izdebska-Szanda, I., Angrecki, M. \& Matuszewski, S. (2012). Investigating of the knocking out properties of moulding sands with new inorganic binders used for casting of non-ferrous metal alloys in comparison with the previously used. Archives of Foundry Engineering. 12 (spec. 2), 117-120.

[10] Izdebska-Szanda, I., Żmudzińska M., Faber, J. \& Perszewska, K. (2012). Moulding sands with new inorganic binders ecology assessment in the aspect of work environment. Archives of Foundry Engineering. 12(3), 115-120.

[11] Regulation of the Minister of Labour and Social Policy of 16 June 2009 - Journal of Laws No. 105, item. 873.

[12] Regulation of the Minister of Labour and Social Policy of 29 July 2010 - Journal of Laws No. 141, item. 950. 